\title{
Role of Social Media in Pre-purchase Consumer Information Search: A Uses and Gratifications Perspective
}

\author{
Jing Zhang \\ Professor, School of management, Huazhong University of Science and Technology, Wuhan, P.R. China \\ Email: jingzhang@hust.edu.cn
}

Rizwan Shabbir

PhD Candidate, School of management, Huazhong University of Science and Technology, Wuhan, P.R. China

Email: rizwanshabbir@hust.edu.cn

Mujeeb-ur-Rehman Abro

Assistant Professor, Shah Abdul Latif University, Khairpur Mir's, Sindh, Pakistan

Email:abrosaab@hotmail.com

\section{Doi:10.5901/mjss.2015.v6n1p11}

\section{Abstract}

The ICT's brought new opportunities for gathering pre-purchase product information. With the help of social media, Consumer Information Search (CIS) has been more refined and specified. The purpose of this study is to identify the need categories of pre-purchase Consumer Information Search based on Uses and Gratifications theory. The model was examined through fully structured questionnaire by using bivariate and factor analysis on a sample of 246 respondents. This study was conducted in Chinese context; therefore results and implication are limited because western social media is quite different than eastern social media. The contribution of this study presented four social media need categories that influence consumer information search (cognitive, social integrative, affective and personal integrative). The finding showed that entertainment and pleasure with social interactions are vital need categories for pre-purchase information search. For enhancing CIS behavior, marketing managers have to provide more information about product \& its usage and should use consumer engagement tools for increasing social interaction such as building online brand communities.

Keywords: Consumer Information Search (CIS), Uses and Gratifications Theory (UGT), Social Media, Consumer Behavior.

\section{Introduction}

Tremendous increase in information technology and communication media has altered the ways of consumer behavior. In order to purchase a product, consumer has to make a decision which relies on the information gathered through prior interaction with that product by means of different communication channels (Jepsen, 2007, Srinivasan, \& Ratchford, 1991). With the popularity and utility of social media, internet becomes more preferable for pre-purchase information search about the product/service that consumer intends to buy. Schmidt \& Spreng (1996) defined information search as a phase of decision-making in which consumers gather and organize information from various sources prior to making a purchase or re-purchasing the product. Prior studies showed that consumer use internet for searching information regarding product and its usage (Fallows, 2005). Thus, this study has investigated the perceived benefits by using social media could provide large amount of information, pleasure, leisure time and saving cost for hiring sales-personal (e.g. Wolfinbarger \& Gilly, 2001, Bellman et al., 2006).

Despite the fact, pre-purchase consumer information search (CIS) about consumer attitudes through social media marketing channels has catered enormous attention in recent years (Okazaki, 2006). Thus, multinational and national corporations are spending huge marketing budgets to take benefit of this business opportunity by offering services and information about products and brands. However, limited literature has described psychological drivers that motivate consumer to search product information on social media and its practical implication for marketers. To fill this knowledge gap, the objective of this study is to examine the consumer perception for pre-purchase CIS by using social media as an information search tool. This relationship is examined by using psychological and information processing factors based 
on Uses and Gratifications theory. Based on objectives, three research questions are pursued: Firstly, to replicate the finding of pre-purchase information search based on consumer involvement in particular product/service. Secondly, to get insights about consumer need categories for obtaining pre-purchase product/service information on social media. Lastly, to extract need categories which are vital for CIS pattern based on social media. These patterns could be used to measure different aspects of consumer behavior about pre-purchase information search.

In the next section, we reported existing literature on pre-purchase CIS and its implication in social media after that, a conceptual model is proposed on the ground of Uses and Gratification theory. Later, we describe methodology and empirical findings that presented managerial implications and directions for future research.

\section{Literature Review}

\subsection{Internal and external CIS}

There are two classifications of information sources which include internal and external sources (Moore \& Lehmann, 1980). According to Punj \& Staelin (1983) internal sources of product information search specify the consumer thoughts that gather information based on previous experience and searches during daily activities or interactions with the product. The internal sources are called as internal search which is very hard to investigate because it is based on consumer thoughts and memory (Beatty \& Smith, 1987). On the other hand, external sources of product information search refers to those information sources which provide information through some medium such as sales-persons, friend \& family, print and media advertisements and marketing agencies. This study aimed to explore the need categories of CIS behavior for external product information search.

Large amount of literature have explored external sources of product information search. Such as Claxton, Fry and Portis (1974) investigated in-store \& out-store determinants, whereas Capon and Lutz (1979) explored the role of independent agencies, commercial media and other consumers' role in product information search. With the introduction of new technologies and improvement in marketplaces, the external search of product information takes new aspects based on marketer-control, re-seller, personal, third-party and direct factors (Schmidt and Spreng, 1996). Moreover, there are two major classification of external consumer information search; First group constitute on pre-purchase information search which are goal-orientated, while second group comprise on on-going purchase information search which are regular or general activities by consumer.

Prior researches on external CIS have discussed consumer's intentions to collect information for particular product/service with a purpose to decrease the risk associated to that product/service. The studies of Hauser, Urban, \& Weinberg (1993) investigated the intensity and duration of CIS behavior, Urbany, Dickson, \& Kalapurakal (1996) explored the information sources and time spent on each interaction. These studies concluded that external information sources are very vital for consumer to make a decision about the product/service. The factors that influence the purchase decision vary due to the medium of interaction which transforms itself from traditional media to social media. Since, the social media have potential to carryout easy interaction but these interactions depend on the activities from other consumers which include posting a feedback/information about the product/service.

On the contrary, CIS has extrinsic and intrinsic motives involved in it. The extrinsic motives include functional, cognitive and specific goal-oriented benefits while intrinsic motives include hedonic, self-esteem and unintended benefits. The product attributes also explained the information source because certain sources are vital for gathering specific information such as; if any individual wants to experience a product, he/she will go to the store rather than reading other consumers posts/messages about their experiences.

\section{$2.2 \mathrm{ClS}$ through internet}

Prior studies concluded that information search through internet is economical, saving time and provide more comprehensive product description to consumers (Peterson \& Merino, 2003). Such information search has transformed from traditional usage of internet to more advanced and reliable sources. For instance, during early 1990's product information was only available on company website or catalogues but nowadays multiple sources provide product information such as social media, blogs, emails etc. On the other hand, perception of a consumer regarding the benefits of the product information on internet was less interesting or relevant as compared to physical product information. Specifically, product information provided on social media by the company or its existing consumers must create factors of trust because new consumers have to judge that product information for making purchase decision (Jepsen, 2007).

However, the interest in a specific product itself enhances consumer information search because social media has 
global reach thereby creates lots of ways for consumers to search relevant information (Chaudhuri, 2000). The higher interest in specific product could increase product knowledge that impacts the purchase decision. There are two kinds of advantages that could be attained by consumer for pre-purchase information search on social media. First, it brought socialization for consumer and secondly, it gave specific information about product that consumers prefer according to their desire. In daily life, consumer pays more concentration to some information sources such as bill-boards, print ads, promotional campaigns \& social-media information. That's the reason why it is essential to recognize the effective information source and consumer behavior based on consumer interaction and trust. From marketing perspective, advancement in technologies demanded marketers to draw insight about the role of social media in pre-purchase consumer information search (Ratchford et al., 2003). CIS has been studied by various researchers based on consumer behavior (see; Srinivasan \& Ratchford, 1991, Ratchford, Lee, \& Talukdar, 2003) so, there are three basic behaviors that explained consumer information search practices: Firstly the sources of information used by consumer, secondly the quantity of information searched and lastly by what means consumer adopts to search that information. In previous literatures, all these aspects of consumer information search have been investigated from different means and sources. The work of Ratchford et al., (2001) concluded that the antecedents of information search could change CIS because it depends on the sources from which product information is gathered. The amount of information searched by consumer is most important while making a purchase decision because it explained the intention/interest in the product based on its perception (Beatty and Smith, 1987). The information searched by consumer could also be a part of their ongoing search process which is a different aspect from pre-purchase search because, in ongoing search process the product information required is specific and guide consumers in re-purchase decision making (Kelly, 1968). The product information gathered by consumer in his/her pervious search has a remarkable effect on future purchase due to product knowledge and information provided on internet. However, this study focused on the need categories of pre-purchase consumer information search by using social media as a source of information.

\subsection{Uses \& Gratifications theory in social media}

Uses \& gratifications theory describes how different media sources (such as social media, electronic media, print media) are employed to satisfy the needs of consumers having different behaviors. The work of Katz, Gurevith, \& Haas (1973) concluded that media sources are differentiated based on the consumer needs through which he/she satisfies and perceive more information as compared to others. This theory considered social and psychological behavior of individuals and integrated them into five different groups. The primary scope of uses \& gratifications theory unfolds the behavior of individuals, motives \& relationship between these variables (Rubin, 2009). The studies which were carried-out based on uses \& gratifications perspective analyzed the needs of individuals that are gratified through media or how gratifications created individual needs based on social media. Thus, for that reason we employed U\&G theory for analyzing consumer needs regarding information search process.

The work of Ebersole (2000) extracted eight motivational factors about web usage of college students based on U\&G theory. It explored variables such as research, accessibility, social interaction, product information \& technical support as students' needs that are required to be fulfilled. The study of Shao (2009) investigated individual's engagement behavior of user- generated media which concluded that individual's engagement was gratified through information, pleasure and emotion management needs. Other than specific purpose for product information search, hedonic benefits are the major objective for consumer shopping behavior (Babin et al., 1994).

In social media, U\&G theory was examined by various scholars based on their research context such as Lampe et al. (2010) explored motivations that provide tools for content creation, participation by the members \& future intention to participate in an online brand community. Moreover, it contributed to represent the behavioral approach of individuals towards content-generation. For predicting the content of information, the work of Haridakis \& Hanson (2008) concluded that individual's engagement in a specific media could be predicted by applying Uses \& Gratifications perspective and comprised on individual's needs that are gratified by adopting different motivational factors. The work of Papacharissi \& Mendelson (2011) conducted a study in which they categorized motives for Facebook users that involved habitual passtime, entertainment, expressive information sharing and others. This study concluded that individual's motivation to participate in a social media to gratify information sharing \& social interaction that produce more knowledge about specific product or event.

\section{Conceptual Framework and Hypotheses Development}

The study of Srinivasan (1990) concluded that consumer information search has three primary theoretical ways based on 
which consumers seek for information: First approach is based on motivational or psychological factors which include variables that are related to individual behavior, product-class and goal-orientated, Second approach is based on economic factor which incorporates the usage and value of cost-benefit framework for examining information search, Third approach is based on information processing method which comprise on the individuals' memories and cognitive behavior or internal consumer information search process. For this study, we incorporated psychological and information processing factors because using social media provide consumers with a platform to gather information about any particular product/service. This approach also presented a specific behavior regarding information search and productclass. Based on literature review and research problem, we formulated a conceptual framework as shown in Figure I.

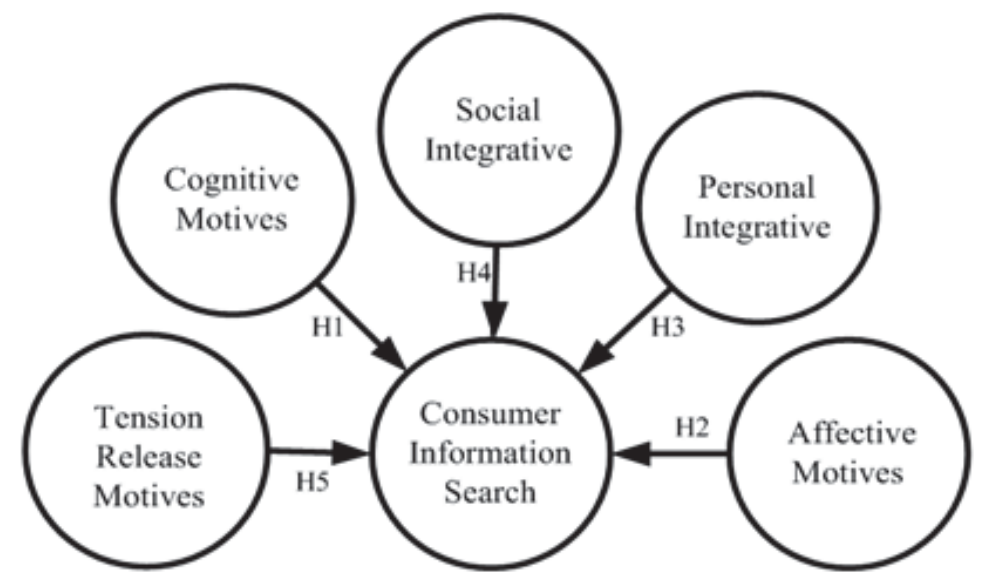

Figure I: Proposed framework of Consumer Information Search

The Uses \& Gratification theory mentioned above comprised on five needs categories that are: cognitive, affective, personal-integrative, social integrative and tension-release. Firstly, cognitive needs include information sharing and knowledge with other individuals. It relates different actions that engage consumers in everyday tasks such as updating status, sharing information with friends, reading shared articles \& status and acquiring information about favorite product or service. Smock et al. (2011) stated that cognitive need such as expressive information sharing has positive influence on different features that involve consumer to acquire and share related information with other consumers for the purpose to create brand trust and loyalty. Acquiring information is one of the most accepted motivational factors that attach consumers for knowledge sharing and information dissemination. Through social media, such cognitive needs become core necessity for sharing interests and keeping friends and peers updated about the things that are going around them. The work of Brandtzæg and Heim (2009) concluded that $10 \%$ of social media users are motivated to acquire information and knowledge from the status \& shared articles by friends \& peers. Such information includes updated fashion trends, cultural events, comments about product/services and etc. Therefore, we proposed that:

$H_{1}$ : Cognitive motives have a positive influence on the pre-purchase consumer information search.

Secondly, affective needs include emotional attachment \& feeling of the consumer about the product/service. With respect to social media, affective needs provide firms with information about pleasing consumers which they desire to acquire. To develop emotional attachment \& feeling for the product/service, enjoyment performs influential role in building consumer behavior about the product that consumer want to search (Lin \& Lu, 2011). The affective needs also provide platform to interact with other people \& through such emotional attachment, collecting and sharing experiences regarding product development \& services (Li \& Bernoff, 2008). The basic assumption behind every medium of communication is to entertain \& gratify audiences similarly in social media; affective needs also played a vital role in fulfilling the desires which provide relaxing environment to consumer for making a purchase decision. Thus, we proposed that:

$\mathrm{H}_{2}$ : Affective motives have a positive influence on the pre-purchase consumer information search.

Thirdly, personal-integrative needs contain individual credibility, status about the satisfaction that he/she felt after the information which was required from the sources. Moreover, personal-integrative needs involved consistent information about the product/service. With respect to social media, such personal integrative needs indicate the consumer behavior about the information search and sources that guide consumers to satisfy with his/her desired results. Companionship motives are one of the significant components for consumers, who want to make communication with his/her friends or peers, for example: chatting with online users (consumers) produce valuable information (Smock et al., 
2011). A study about Facebook recommended that social media contribute in building credibility, emotional support and status for users through participating and sharing information among online-friends (Vitak, Ellison \& Steinfield, 2011). Thus, personal-integrative needs in social media provide consumers with a perception about the engagement and status that is not possible in an offline situation. Furthermore, research in social media has explained the fact that individuals engage themselves in maintaining their relationship with other individuals by frequent interaction at different forums and chat-rooms which resulted in updating their status and creditability among consumers. Thus, we assumed that:

$\mathrm{H}_{3}$ : Personal integrative motives have a positive influence on the pre-purchase consumer information search.

Fourth category of needs contain social-integrative needs which are characterized as an interaction behavior of individual with friends and family. Consumers usually attempt to stay connected with their family and friends by means of different media sources such as dedicating songs to love-ones, sending message through print-media to friends \& family and chatting with online friends via social media. These social interactions provided valuable information to the individual about any product/service that he/she wants to search. Such social interactions provide recommendations to consumers, who are searching for product information. Meanwhile, the consumers also ask existing consumers for their recommendation/advice about purchasing a product/service by posting questions on different social media applications. The study of Smock et al. (2011) concluded that social communication between individuals on social media influence the comments, wall-post and likes which presented various sources of valuable information to consumers, who are seeking for help/guidance. Therefore, we assumed that:

$\mathrm{H}_{4}$ : Social integrative motives have a positive influence on the pre-purchase consumer information search.

Lastly, tension release needs involves motives which lead individuals to find patterns for enjoyment, pleasure and recreation. Tension release needs provide individuals with an easy accessible medium through which he/she can prevent himself/herself from pressure of daily habitual activities. The activities on social media have primarily provoked by gratifications that are attained through surveillance, communication and escapism among individuals (Miller, 1995). Tension release needs benefit individuals to gratify their want/desire by connecting with other individuals by means of quick, reliable and accurate information seeking. Moreover, social media enhanced the motives that assist individuals in escapism by engaging them with new people which provide most opinions and ideas about selecting/purchasing a product/service.

$H_{5:}$ Tension release motives have a positive influence on the pre-purchase consumer information search.

\section{Research Methodology}

Prior studies related to communication and marketing implemented ethnographic research philosophy to investigate communicative attitude of target audience (Rubin et al., 2005). It is a fundamental study of cultures and communities which is specially constructed for exploring cultural phenomena. Based on the research objectives, this methodology collected data which examined consumer behavior on internet by exploring the required perception of respondent. As, this study investigate consumer attitudes in-terms of information search in online communities operated in China. Therefore, ethnographic research technique guides us to explore need categories of respondents while interacting at social media and provide valuable outcome based on consumer needs about pre-purchase CIS.

\subsection{Measurement scales}

The measurement of key factors for this research model is borrowed from prior studies with a little modification in their context to make a better fit. The summary of constructs and its description is given in Table I. As we discussed earlier, the usage of internet for product information search provide us the relative internet usage and the relationship between these variables should be high to strengthen our proposed relationship. Therefore, we asked respondents about internet usage on a five-point likert scale of "little-time... much-time". Based on the research problem, we asked respondents about their product information search behavior on internet and their interest in that specific product such as the knowledge about that product/service that they are searching for. To measure these variables, we used five-point scale from "little-interest....large-interest". 
Table I: Description and scales of measurement

\begin{tabular}{l|l|l}
\hline Construct & Description & a \\
\hline Internet usage/day & By Novak, Hoffman and Yung (2000) & 0.73 \\
\hline Time spent on internet/day & Adopted from Jepsen (2007) & 0.67 \\
\hline Online time spent on product search & By Peterson \& Merino (2003) & 0.74 \\
\hline Interest in that product & Newly developed & $\begin{array}{l}\text { Developed by Katz, Gurevitch, and Haas (1973) \& } \\
\text { adopted from the study of Smock et.al (2011) }\end{array}$ \\
\hline Affective need & $\begin{array}{l}\text { Developed by Katz, Gurevitch, and Haas (1973) \& } \\
\text { adopted from the study of Smock et.al (2011) }\end{array}$ & 0.70 \\
\hline Personal Integrative need & $\begin{array}{l}\text { Developed by Katz, Gurevitch, and Haas (1973) \& } \\
\text { adopted from the study of Smock et.al (2011) }\end{array}$ & 0.67 \\
\hline Social Integrative need & $\begin{array}{l}\text { Developed by Katz, Gurevitch, and Haas (1973) \& } \\
\text { adopted from the study of Smock et.al (2011) }\end{array}$ & 0.68 \\
\hline Tension Release need & $\begin{array}{l}\text { Developed by Katz, Gurevitch, and Haas (1973) \& } \\
\text { adopted from the study of Smock et.al (2011) }\end{array}$ & 0.66 \\
\hline Consumer information search & Adopted from To, Lia0, \& Lin (2007) & 0.75 \\
\hline
\end{tabular}

In social media, the interest of user (consumer) played vital part in commenting/liking or providing feedback to other users on their posts/status. To investigate the primitive objective, we adopted user's motives for product information search based on the work of Katz, Gurevitch and Haas (1973). To measures these consumer need categories, we borrowed scale from the study of Smock et.al (2011) which used five-point likert scale from "strongly disagree...strongly agree". We constructed five needs categories and each need has been measured through three variables. The need categories for pre-purchase consumer information search includes (cognitive, affective, social-integrative, personal-integrative and tension release need). For pre-purchase consumer information search, we designed five variables that measure information search behavior on social media based on the study of To, Liao, \& Lin (2007) \& Moorthy, Ratchford, and Talukdar (1997).

\subsection{Sample and Procedure}

We gathered a final dataset of 246 out of 300 respondents with a response rate of $82 \%$. As, most of the questions related to uses and gratifications theory were adopted from previous studies just to fit them in our context, we changed their language for easy understanding and quick response. After that, pilot study has been conducted to review the questionnaire and the context. We published the final questionnaire and sent the link by using different social media websites being operated in mainland China such as (Wechat, QQ Zone, Weibo \& RenRen). The data was collected during the period March, 2014 to June, 2014. For statistical analysis, we used bivariate and factor analysis for investigating research problem. All the relationships are examined at the significance level of $p<0.05$ and reliability of all the constructs are measured by Cronbach's alpha.

\subsection{Demographics}

The demographics represents that male and female respondents are quite equal, male respondents are $48 \%$ while female representation in this study is about $52 \%$. Respondents under 20 years comprise about $73.6 \%$. The education attained by respondents shown that mostly are graduates which comprise about $77.6 \%$. The family income showed that $57.3 \%$ of respondents earn less than 20,000 CYN in a month. The summary of respondents is given in Table II. The demographic variables showed that our respondent group is teen-agers because they use social media more than any other age-group. Moreover, the most regular used social media by respondents is QQ zone which comprise on $64.4 \%$ followed by RenRen which comprise on $24 \%$. 
Table II: Profile of respondents

\begin{tabular}{l|l|c}
\hline \multicolumn{2}{l|}{ Variable (N=246) } & Percentage \\
\hline \multirow{4}{*}{ Age in Years } & $<20$ & $73.6 \%$ \\
\cline { 2 - 3 } & $20-30$ & $18.7 \%$ \\
\cline { 2 - 3 } & $>30$ & $7.7 \%$ \\
\hline \multirow{3}{*}{$\begin{array}{l}\text { Attained } \\
\text { Gender }\end{array}$} & Bachelor degree & $77.6 \%$ \\
\cline { 2 - 3 } & Master degree & $17.1 \%$ \\
\cline { 2 - 3 } & PhD or more & $5.3 \%$ \\
\hline \multirow{4}{*}{$\begin{array}{l}\text { Family Income } \\
\text { per Month }\end{array}$} & Male & $48.4 \%$ \\
\cline { 2 - 3 } & Female & $51.6 \%$ \\
\hline \multirow{4}{*}{$\begin{array}{l}\text { Regular used } \\
\text { Social Media }\end{array}$} & $<20,000$ CYN & $57.3 \%$ \\
\cline { 2 - 3 } & $20,000-50,000$ CYN & $27.2 \%$ \\
\cline { 2 - 3 } & $50,0001-100,000$ CYN & $10.6 \%$ \\
\cline { 2 - 3 } & $100,000-150,000$ CYN & $4.1 \%$ \\
\cline { 2 - 3 } & $>150,001$ CYN & $0.8 \%$ \\
\hline
\end{tabular}

\section{Result}

The link between internet usage and online search behavior is examined through correlation between these two variables. The outcome showed that consumer likes to use "internet" for product search with a mean of 3.02 and "Time spent on searching product" with a mean of 3.07, it showed that consumer has interest in acquiring product information through social media. Therefore, the more internet usage per day the more consumers' search for product information through social media is observed. When a user (consumer) spent time on searching product information it's due to consumer interest in that particular product. The correlations among the variables provided significant results which guide us towards next step of investigating research hypotheses. The summary of relationship between internet usage and online product search behavior is given in Table III. The finding indicated that users spent time on internet and also searches to product information but it doesn't mean that they are interested in purchasing that product/service.

Table III: Relationship between using internet and online search for products

\begin{tabular}{|c|c|c|c|c|c|c|}
\hline & Mean & $\begin{array}{l}\text { Std. } \\
\text { Dev }\end{array}$ & $\begin{array}{l}\text { Interest } \\
\text { using }\end{array}$ & $\begin{array}{l}\text { Time Spent on } \\
\text { internet Per day }\end{array}$ & $\begin{array}{l}\text { Time spent on } \\
\text { searching } \\
\text { product }\end{array}$ & $\begin{array}{l}\text { Interest in } \\
\text { the product }\end{array}$ \\
\hline Interest using & 3.02 & 1.03 & 1 & $0.46^{\star \star}$ & $0.58^{\star \star}$ & -0.05 \\
\hline Time spent on internet/day & 2.83 & 0.93 & & 1 & $0.50^{\star \star}$ & 0.10 \\
\hline Time spent on searching product & 2.75 & 0.96 & & & 1 & $0.15^{\star}$ \\
\hline Interest in the product & 3.07 & 1.07 & & & & 1 \\
\hline
\end{tabular}

${ }^{* *} p<0.01,{ }^{*} p<0.05$

Principal component analysis based on rotated factor pattern extracted the need categories for pre-purchase product information search based on Eigen-value more than 1.00 and sort these uses \& gratifications need categories according to highest alpha value and variance, only one need category was dropped due to Eigen-value less than 1.00. In general, the outcome of principal component analysis are good based on KMO and Bartlett's test, which revealed that the sampling adequacy is 0.710 which is termed as good and Bartlett's Test having a Chi-Square of 592.49 with significant level of $99 \%$. The rotated factor pattern summarized need categories that played important role in pre-purchase consumer information search on social media as shown in Table IV. Therefore, the first need category is most valuable in determining any consumer purchase behavior. Thus, cognitive need category emerged as most vital factor in prepurchase consumer information search with $\alpha=0.740$ by explaining variance of 17.06 . Cognitive need included enhancing knowledge, obtaining solutions and searching for advancement in products. The second need category that was extracted was social-integrative needs with explained variance of 16.03 with $\alpha=0.685$. In this need category, social 
networks, sense of attachment and belonging played role in consumer information search which provided users trust and recommendations from friends/family. Third need category was based on affective needs with $\mathrm{a}=0.638$ by explaining variance of 15.29. The affective needs have provided consumer with an opportunity to find relaxing time, entertainment \& fun/pleasure while searching for product information on social media. Personal-integrative need category was obtained from principal component analysis with $\alpha=0.441$ by explaining variance of 12.57 . This need category was related to consumer personal attributes such as: suitable thing to do or everybody else like that. Tension release need category has been dropped due to eigen-value less than 1.00. The need category measured factors related to pass-time or nothing better to do. Moreover, this need category didn't have significant relationship with time spent on internet for pre-purchase product information search and interest in that specific product.

Table IV: Principal component analysis of information search motives

\begin{tabular}{l|c|c|c}
\hline Motive (Eigen-value) & Loading & a & Variance explained \\
\hline Cognitive Needs & & 0.740 & 17.06 \\
Enhance knowledge about product/usage & 0.835 & & \\
Obtain solution for specific usage & 0.720 & & \\
Enhance/share knowledge about advances in product & 0.764 & & \\
\hline Social integrative Needs & 0.815 & 0.685 & \\
Expand social network (friends/family recommendations) & 0.711 & & \\
Enhance my strength of Attachment & 0.746 & & \\
Enhance my sense of Belonging & & 0.638 & \\
\hline Affective Needs & 0.789 & & \\
Entertain and stimulate my mind & 0.773 & & \\
Derive fun and pleasure & 0.789 & & \\
Enjoyable and relaxing time & & 0.441 & \\
\hline Personal integrative Needs & 0.719 & & \\
Utilize the time well & 0.673 & & \\
Everybody else do that & 0.576 & & \\
Suitable thing to do & & \\
\hline
\end{tabular}

After extracting need categories through principal component analysis, we examined the proposed hypothesis and results showed that all hypotheses are accepted other than tension-release needs because factor analysis excluded the variables that measure tension-release needs for $\mathrm{CIS}$ search on social media. The linear regression showed that prepurchase CIS predicted $\mathrm{R}=32.8 \%$ and $\mathrm{R}^{2}=10.7 \%$ as shown in Table $\mathrm{V}$. The need categories showed that affective needs and social-integrative needs are highly significant as compared with other categories. Thus, a change in consumer affective motives will affect pre-purchase CIS behavior. To engage target and provide them product knowledge, brand managers should provide them entertainment and pleasure on social media. The result indicates that $\mathrm{H}_{1}$ to $\mathrm{H}_{4}$ are supported which means the cognitive, social integrative, affective and personal integrative needs have a positive effect on the consumer information search for a product/service. On the other hand, $\mathrm{H}_{5}$ is rejected which clarifies that tension release needs don't have a positive effect on consumer information search. Moreover, to summarize the results, we can conclude that social interactions play a vital role in searching for product information.

Table V: Regression analysis of pre purchase consumer information search

\begin{tabular}{|c|c|c|c|c|}
\hline \multirow{2}{*}{$\begin{array}{l}\text { Dependent variable } \\
\text { Predictors }\end{array}$} & \multicolumn{4}{|c|}{ Consumer information search } \\
\hline & $\beta$ & Sig. & $T$ & VIF \\
\hline a & $1.067^{\star \star}$ & .00 & 3.65 & \\
\hline Cognitive needs & $.103^{*}$ & .05 & 1.92 & 1.17 \\
\hline Social integrative needs & $.127^{\star}$ & .02 & 2.21 & 1.07 \\
\hline Affective needs & $.142^{*}$ & .02 & 2.26 & 1.00 \\
\hline Personal integrative needs & $.099 *$ & .03 & 2.15 & 1.20 \\
\hline $\mathrm{R}$ & .328 & & & \\
\hline $\mathrm{R}^{2}$ & .107 & & & \\
\hline Adjusted R2 & .093 & & & \\
\hline
\end{tabular}




\section{Discussion and Conclusion}

This study brought valuable insights about CIS in social media from uses and gratifications perspective, which elaborated need categories that engage consumers in pre-purchase product information search. The results fully supported four need categories (affective, social integrative, personal-integrative and cognitive) other than tension-release needs. Prior studies also supported the research propositions for instance, the work of Wolfinbarger \& Gilly (2001) also concluded that quantity of product/service information on internet have a positive influence on consumer information search. The use of social media for a pre-purchase CIS behavior conveyed the dominant type of need that consumer adopt for collecting relative information. Various studies investigated the quantity of product information and role of social media such as Bellman et al., 2006, but in specific we tried to explore the interest and need categories of consumer in collecting prepurchase information about a product. The findings show that need categories motivate the consumer to take interest in the information search process of a product /service which impact user's engagement on social media by reviewing and analyzing opinions from other users.

The availability of information about a product/service on internet guides the users to collect more specific and accurate information and its related opinions. Therefore, this study supported the work of Hoque and Lohse (1999) which mentioned that easy accessibility and compatibility of users with different social media applications drive them to use social media for searching productive information such as: feedback from other users about the product/service. This is not an influential factor that effects the CIS process but it extends the consumer behavior to retrieve the information about any product/service that consumer want to find out. The current adoption of ICT's made more space for consumers to gather pre-purchase information about a product/service. The need categories that motivate consumers to search for information illustrate the user behavior and requirement for that product/service.

In this regard, the relationship between need categories and CIS showed that affective need and social-integrative need played important role because consumer was driven to search for product information due to pleasure, entertainment or recommendations from friends and family. The affective need express entertainment, fun or pleasure element for consumer in pre-purchase information search and social-integrative need worked as relationship marketing for consumer. This indicated that consumer needs categories for pre-purchase information search provide aspects of consumer behavior. However, consumer receives large quantities of information on social media but feel free to accept those aspects which provide him/her satisfactory information. The empirical evidence provides additional support based on the work Novak, Hoffman, and Yung (2000) which discussed the usage of internet for product information. The results concluded that usage of social media is directly proportional with engagement of user in everyday life. This intention is a part of social-integrative need which resulted in useful opinions and practical feedback from other users about the product. It also reflects that consumer increases its pre-purchase experience and socializing with current-consumers provide first-hand information about product/service other than presented by the company itself. Increased engagement in social media activities affects every day behavior and actions of individuals. Therefore, we conclude that socialization affects need categories which influence pre-purchase consumer information search process.

The social media is a cyberspace for individual to participate and engage in different activities. The norms of social media also influence CIS behavior because if we classify needs into two groups: first group involves consumer feeling and interaction factors and second group of needs involves product information and consumer credibility factors. This indicates that consumer communication with other users (friends \& family) and desire of product information impact prepurchase product information. This study supported the work of Peterson and Merino (2003) which suggested that cyberspace has transformed the search patterns that affect the consumer behavior.

Moreover, the study explained that consumer attachment with social media is due to time spent/day and availability of information. This indicates that traditional media and typical marketing communications are replacing with social media and IMC (integrated marketing communications). Therefore, the product information provided on social media is opinionbased, more-knowledge and valuable which create opportunities for a new segmentation in existing market. The purchasing decision process also considers evaluation of alternatives in marketplace, so these need categories influence those factors through social-integrative needs (Shim et al., 2011).

\section{Managerial Implication and Limitations}

All businesses around the world either multinational or national have developed their websites and social media networks to facilitate existing and new consumers. Previously, consumers acquired information about product through different catalogues, display centers and advertisements but after the transformation of traditional media into web-based media, the catalogues are changed into web-sites and thus\& advertisement has become digital. During last decade, web-based 
media have now transformed itself into online brand communities that fulfill the needs of consumers. Through these social media applications, consumers participate and engage in different activities to retrieve required product information. This study suggests that future research should identify motives of needs, specific to product category. The motives will express the consumer behavior that will present their opinion about actual purchase decision.

From marketer's perspective, the professionals should involve social media applications as a tool to search product information. This study recommends that consumers are switching from traditional information search tools to ICT based product information search tool. This suggests that marketing professionals should design their marketing strategies by catering consumer demand based on the categorization of need extracted by this study. Moreover, the marketing professionals should initiate activities that must engage consumers for product participation and information search before purchasing the product. This kind of consumer information search will guide the marketers to increase loyalty and consumer experience about a product/service. The product information searched by the consumer on social media based on need categorization conclude the type of need that must be required to be fulfilled before retrieving information regarding other needs. From theoretical perspective, this study suggests that companies could use varied strategies for consumer using social media. These strategies should be formulated based on interest in product category, time spent, consumer intention and need categories. This theoretical contribution will open new domain in marketing and brand management.

There are few limitations that are needed to be considered while conducting future research like; we have mentioned that this study is only examined within Chinese context. This context affects the results and conclusion because Chinese social media is different in many ways as compared with western social media. Moreover, a comparison between European consumer and Asian consumer will explore more in-depth factors with respect to social media. As, we only investigate external pre-purchase CIS patterns based on psychological factors, thus our scope becomes very limited. Future research directions should consider other theoretical approaches as well.

\section{Acknowledgement}

This research is sponsored by the "National Natural Science Foundation of China under Grant 71272125" and "Fundamental Scientific and Research Program of Chinese Central Universities under Grant 2014QN207

\section{References}

Babin, B.J., William, R.D., Mitch, G. (1994). Work and/or fun: measuring hedonic and utilitarian shopping value. Journal of Consumer Research 20 (4), 644-656. http://dx.doi.org/10.1086/209376

Beatty, S. E., \& Smith, S. M. (1987). External search effort: An investigation across several product categories. Journal of Consumer Research, 14, 83-95. http://dx.doi.org/10.1086/209095

Bellman, S., Johnson, E. J., Lohse, G. L., \& Mandel, N. (2006). Designing Marketplaces of the Artificial with Consumers in Mind: Four Approaches to Understanding Consumer Behavior in Electronic Environments, Journal of Interactive Marketing, 20, 21-33 http://dx.doi.org/10.1002/dir.20053

Bloch, P. H., Ridgway, N. M., \& Sherrell, D. L. (1989). Extending the Concept of Shopping: An Investigation of Browsing Activity, Journal of the Academy of Marketing Science, 17, 13-21 http://dx.doi.org/10.1007/BF02726349

Brandtzæg, P. B., \& Heim, J. (2009). Why people use social networking sites. In Online communities and social computing (143-152), Springer Berlin Heidelberg

Butler, P., \& Peppard, J. (1998). Consumer purchasing on the Internet: Processes and prospects. European Management Journal, 16(5), 600-610. http://dx.doi.org/10.1016/S0263-2373(98)00036-X

Capon, N., \& Lutz, R. J. (1979). A model and methodology for the development of consumer information program, Journal of Marketing, 43(1), 58-67. http://dx.doi.org/10.2307/1250759

Chaudhuri, A. (2000). A Macro Analysis of the Relationship of Product Involvement and Information Search: The Role of Risk. Journal of Marketing Theory and Practice, 8, 1-13.

Cheema, A., \& Papatla, P. (2010). Relative importance of online versus offline information for Internet purchases: Product category and Internet experience effects. Journal of Business Research, 63(9), 979-985. http://dx.doi.org/10.1016/j.jbusres.2009.01.021

Claxton, J. D., Fry, J. N., \& Portis, B. (1974). A taxonomy of pre-purchase information gathering patterns. Journal of Consumer Research, 1(3), 35-42. http://dx.doi.org/10.1086/208598

Ebersole, S. (2000). Uses and gratifications of the web among students, Journal of Computer - Mediated Communication, 6(1)

Fallows, D. (2005). Tracking Online Life: How Women and Men Use the Internet. Pew Internet and American Life Report (2005). [Online]. Available at www.pewinternet.org

Froget, J. R. L., Baghestan, A. G., \& Asfaranjan, Y. S. (2013). A Uses and Gratification Perspective on Social Media Usage and Online Marketing. Middle-East Journal of Scientific Research, 15(1), 134-145

Haridakis, P., \& Hanson, G. (2008). YouTube users watching and sharing the news: A uses and gratifications approach. Journal of 
Electronic Publishing, 11(3)

Hauser, J. R., Urban, G. L., \& Weinberg, B. D. (1993). How consumers allocate their time when searching for information. Journal of Marketing Research, 30, 452-466. http://dx.doi.org/10.2307/3172690

Jepsen, A. L. (2007). Factors affecting consumer use of the Internet for information search. Journal of Interactive Marketing, 21(3), 2134. http://dx.doi.org/10.1002/dir.20083

Katz, E., Gurevith, M., \& Haas, H. (1973). On the use of the mass media for importantthings. American Sociological Review, 38, 164181. http://dx.doi.org/10.2307/2094393

Kelly, R. F. (1968). The search component of the consumer decision process: A theoretical examination. In M. A. King (Ed.), Marketing and the new science of planning (pp. 271-274). Chicago: American Marketing Association.

Klein, L. R., \& Ford, G. T. (2003). Consumer search for information in the digital age: an empirical study of prepurchase search for automobiles. Journal of interactive Marketing, 17(3), 29-49 http://dx.doi.org/10.1002/dir.10058

Klein, L. R., \& Ford, G. T. (2003). Consumer search for information in the digital age: an empirical study of prepurchase search for automobiles. Journal of interactive Marketing, 17(3), 29-49. http://dx.doi.org/10.1002/dir.10058

Lampe, C., Wash, R., Velasquez, A., \& Ozkaya, E. (2010, April). Motivations to participate in online communities. In Proceedings of the SIGCHI Conference on Human Factors in Computing Systems (pp. 1927-1936). ACM.

Li, C., \& Bernoff, J. (2008). Groundswell: Winning in a world transformed by social technologies. Boston, MA: Harvard Business School Press.

Lin, K. Y., \& Lu, H. P. (2011). Why people use social networking sites: An empirical study integrating network externalities and motivation theory. Computers in Human Behavior, 27(3), 1152-1161. http://dx.doi.org/10.1016/j.chb.2010.12.009

Lin, Q., \& Lee, J. (2002). Consumers' information search when making investment decisions (Doctoral dissertation, University of Georgia).

Miller, H. (1995). The presentation of self in electronic life: Goffman on the Internet. In Embodied knowledge and virtual space conference (Vol.9)

Moore, W. L., \& Lehmann, D. R. (1980). Individual differences in search behavior for a nondurable. Journal of Consumer Research, 7 , 296-307. http://dx.doi.org/10.1086/208817

Moorthy, S., Ratchford, B. T., \& Talukdar, D. (1997). Consumer Information Search Revisited: Theory and Empirical Analysis. Journal of Consumer Research, 23, 263-277. http://dx.doi.org/10.1086/209482

Novak, T. P., Hoffman, D. L., \& Yung, Y. (2000). Measuring Customer Experience in Online Environments: A Structural Modeling Approach, Marketing Science, 19, 22-42 http://dx.doi.org/10.1287/mksc.19.1.22.15184

Okazaki, S. (2006). What do we know about mobile internet adopters? A cluster analysis. Information \& Management, 43(2), $127-141$. http://dx.doi.org/10.1016/j.im.2005.05.001

Papacharissi, Z., \& Mendelson, A. (2011). Toward a new(er) sociability: Uses, gratifications and social capital on Facebook. In S. Papathanassopoulos (Ed.), Media perspectives for the 21st century (pp. 212-230). New York: Routledge

Peterson, R. A., \& Merino, M. A. (2003). Consumer Information Search Behavior on the Internet. Psychology \& Marketing, 20, 99-121. http://dx.doi.org/10.1002/mar.10062

Punj, G. N., \& Staelin, R. (1983). A model of consumer information search behavior for new automobiles. Journal of Consumer Research, 9, 366-380. http://dx.doi.org/10.1086/208931

Ratchford, B.T., Lee, M.S., \& Talukdar, D. (2001). A Model of Consumer Choice of the Internet as an Information Source. International Journal of Electronic Commerce, 5(3), 7-21.

Ratchford, B. T., Lee, M. S., \& Talukdar, D. (2003). The impact of the Internet on information search for automobiles. Journal of Marketing Research, 40(2), 193-209. http://dx.doi.org/10.1509/jmkr.40.2.193.19221

Rubin, R. B., Rubin, A. M., and Piele, L. J. (2005). Communication Research: Strategies and Sources. Belmont, California: Thomson Wadworth.

Rubin, A., (2009). Uses and gratifications perspective on media effects. In: Bryant, J., Oliver, M.B. (Eds.), Media effects: Advances in theory and research (3rd ed.). Routledge, New York, pp. 165-184.

Schmidt, J. B., \& Spreng, R. A. (1996). A proposed model of external consumer information search. Journal of the Academy of Marketing Science, 24, 246-256. http://dx.doi.org/10.1177/0092070396243005

Schmidt, J. B., \& Spreng, R. A. (1996). A proposed model of external consumer information search. Journal of the Academy of Marketing Science, 24(3), 246-256. http://dx.doi.org/10.1177/0092070396243005

Shao, G. (2009). Understanding the appeal of user-generated media: a uses and gratification perspective. Internet Research, 19(1), 725. http://dx.doi.org/10.1108/10662240910927795

Shim, S., Eastlick, M. A., Lotz, S. L., \& Warrington, P. (2001). An online prepurchase intentions model: The role of intention to search:

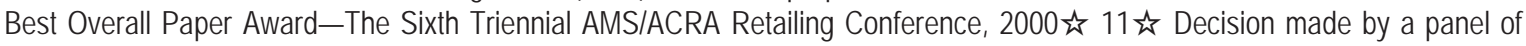
Journal of Retailing editorial board members. Journal of retailing, 77(3), 397-416. http://dx.doi.org/10.1016/S00224359(01)00051-3

Smock, A. D., Ellison, N. B., Lampe, C., \&Wohn, D. Y. (2011). Facebook as a toolkit: A uses and gratification approach to unbundling feature use. Computers in Human Behavior, 27(6), 2322-2329. http://dx.doi.org/10.1016/j.chb.2011.07.011

Srinivasan N., \& Ratchford, B. T. (1991). An Empirical Test of a Model of External Search for Automobiles. Journal of Consumer Research, 18, 233-242. http://dx.doi.org/10.1086/209255

Srinivasan, Narasimhan. (1990). "Pre-Purchase External Search for Information." In Review of Marketing. Ed. Valarie E. Zeithaml. 
Chicago: American Marketing Association, 153-189.

To, P. L., Liao, C., \& Lin, T. H. (2007). Shopping motivations on Internet: A study based on utilitarian and hedonic value. Technovation, 27(12), 774-787. http://dx.doi.org/10.1016/j.technovation.2007.01.001

Urbany, J. E., Dickson, P. R., \& Kalapurakal, R. (1996). Price search in the retail grocery market. Journal of Marketing, 60, 91-104. http://dx.doi.org/10.2307/1251933

Vitak, J., Ellison, N. B., \& Steinfield, C. (2011). The ties that bond: Re-examining the relationship between Facebook use and bonding social capital. In System Sciences (HICSS), 2011 44th Hawaii International Conference on (pp. 1-10). IEEE. http://dx.doi.org/10.1109/HICSS.2011.435

Wolfinbarger, M., \& Gilly, M. (2001). Shopping Online for Freedom, Control and Fun. California Management Review, 43, 34-53. http://dx.doi.org/10.2307/41166074 